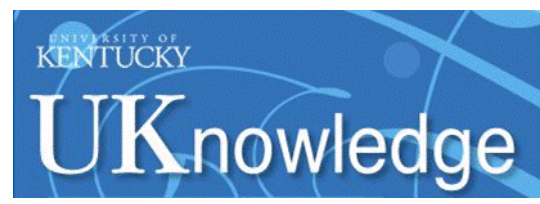

University of Kentucky

UKnowledge

\title{
$9-2015$
}

\section{Interpersonal Competence and Service Leadership}

Daniel T. L. Shek

University of Kentucky

Lu Yu

Hong Kong Polytechnic University, China

Andrew M. H. Siu

Hong Kong Polytechnic University, China

Follow this and additional works at: https://uknowledge.uky.edu/pediatrics_facpub

Part of the Pediatrics Commons

Right click to open a feedback form in a new tab to let us know how this document benefits you.

\section{Repository Citation}

Shek, Daniel T. L.; Yu, Lu; and Siu, Andrew M. H., "Interpersonal Competence and Service Leadership" (2015). Pediatrics Faculty Publications. 206.

https://uknowledge.uky.edu/pediatrics_facpub/206

This Article is brought to you for free and open access by the Pediatrics at UKnowledge. It has been accepted for inclusion in Pediatrics Faculty Publications by an authorized administrator of UKnowledge. For more information, please contact UKnowledge@lsv.uky.edu. 


\section{Interpersonal Competence and Service Leadership}

\section{Digital Object Identifier (DOI)}

https://doi.org/10.1515/ijdhd-2015-0407

\section{Notes/Citation Information}

Published in International Journal on Disability and Human Development, v. 14, no. 3, p. 265-274.

(C) 2015 Walter de Gruyter GmbH, Berlin/Boston

The copyright holders have granted the permission for posting the article here. 


\section{Daniel T.L. Shek*, Lu Yu and Andrew M.H. Siu Interpersonal competence and service leadership}

DOI 10.1515/ijdhd-2015-0407

Received April 12, 2014; accepted June 12, 2014; previously published online August 12, 2015

\begin{abstract}
According to the Hong Kong Institute of Service Leadership and Management, interpersonal competence is an important component of an effective service leader. The present paper introduces a lecture embedded in a service leadership subject that focuses on promoting students' interpersonal competence. Several topics are covered in this lecture. First, concepts and theories about interpersonal competence are introduced. Second, the relevance of interpersonal competence to service leadership is outlined. Third, methods of developing interpersonal competence are presented, particularly different conflict management strategies and assertiveness skills. Finally, conclusions and reflections on students' own interpersonal competence and its relevance to the service leadership in one's professional field are discussed. Different activities have been designed and incorporated in the lecture to facilitate students' active learning and selfreflection. Students are also encouraged to explore their own ways to promote the development of interpersonal competence.
\end{abstract}

Keywords: Hong Kong; interpersonal competence; service leadership; university education.

*Corresponding author: Daniel T.L. Shek, PhD, FHKPS, BBS, SBS, JP, Chair Professor of Applied Social Sciences, Faculty of Health and Social Sciences, Department of Applied Social Sciences, The Hong Kong Polytechnic University, Room HJ407, Core H, Hunghom, Hong Kong, P.R. China, E-mail: daniel.shek@ polyu.edu.hk; Department of Applied Social Sciences, The Hong Kong Polytechnic University, Hong Kong, P.R. China; Center for Innovative Programs for Adolescents and Families, The Hong Kong Polytechnic University, Hong Kong, P.R. China; Kiang Wu Nursing College of Macau, Macau, P.R. China; Department of Social Work, East China Normal University, Shanghai, P.R. China; and Division of Adolescent Medicine, Department of Pediatrics, Kentucky Children's Hospital, University of Kentucky College of Medicine, Lexington, KY, USA

Lu Yu: Department of Applied Social Sciences, The Hong Kong Polytechnic University, Hong Kong, P.R. China

Andrew M.H. Siu: Department of Rehabilitation Sciences, The Hong Kong Polytechnic University, Hong Kong, P.R. China

\section{Introduction}

With an economy dominated by service industries, quality service is one of the most competitive strengths of Hong Kong. Hence, promoting leadership that emphasizes the role of a server instead of a leader is particularly important for Hong Kong to keep its leading position as a top serviceoriented economy. Echoing this call, the Hong Kong Institute of Service Leadership and Management (HKI-SLAM) developed a curriculum framework to promote learning and practice of service, leadership and service leadership in Hong Kong educational institutions, business and individuals. According to this framework, an ideal service leader should possess not only situational specific leadership competences, but also moral character and a caring disposition. The HKI-SLAM curriculum was designed to provide basic guidance for different educational institutions to develop service leaders that are needed in the current Hong Kong society [1].

As to how to cultivate individuals with situational specific leadership competences, moral character and caring dispositions, the social-cognitive approach to motivation [2] and the transformative learning theory [3] have provided strong theoretical bases for the HK-SLAM framework. According to the social-cognitive approach to motivation, intrapersonal and interpersonal competences, moral character and a caring disposition are malleable and can be nurtured. They can be acquired and improved through learning and practice [4]. Regarding the transformative learning theory, by providing learners a chance to examine and challenge their existing ways of interpreting the world, and to open themselves to alternatives (e.g. reflective exercises), personal changes and development can happen in the learners. When the way the learner makes meaning out of the world changes, transformation can take place.

To promote the development of service leadership education in Hong Kong, the HKI-SLAM initiated a project financially supported by the Victor and William Fung Foundation, with eight tertiary institutions supported by the University Grants Committee (UGC) participating in the project [1]. At The Hong Kong Polytechnic University, both credit-bearing and non credit-bearing programs have been conducted. For credit-bearing subjects on service leadership, a two-credit general education subject 
entitled "Service Leadership" was designed and offered to 60 students in the 2012/13 academic year and 89 students in the 2013/14 academic year. The objectives of the subject are to enable students to: (1) learn and integrate theories, research and concepts of service leadership, especially the HKI-SLAM (service leadership and management) conceptual framework; (2) be familiar with essential knowledge, skills, attitudes and values covered in the HKI-SLAM curriculum; (3) develop and reflect on their own moral character, psychosocial competences and caring disposition; and (4) cultivate an appreciation of the importance of service leadership to the development and wellness of oneself, other people and the whole society.

In this paper, one lecture covered in the two-credit general education subject entitled "Service Leadership" at The Hong Kong Polytechnic University is described. This lecture focuses on the cultivation of interpersonal competence in students as a critical competence in service leadership. To become an effective service leader, students need to understand the basic theories and importance of interpersonal competence and be equipped with the related skills. In this lecture, key concepts of interpersonal competence and its relevance to service leadership are first introduced. Students are then encouraged to reflect on their own performance in terms of assertiveness and other interpersonal communication skills. Finally, methods to promote one's own interpersonal competence are recommended.

\section{Content and design of the lecture}

Clear intended learning outcomes are important components of a well-designed lecture that represents what students are expected to know, understand and be able to do after completing the lecture. For the present lecture, several intended learning outcomes were drawn up when developing the curriculum. First, students are expected to understand the concepts related to interpersonal competence after taking the lecture. Second, students shall recognize the factors that affect one's interpersonal competence development. Third, by participating in planned learning experiences, students are expected to appreciate the role of different interpersonal skills (particularly assertiveness) in effective service leadership. Fourth, students are expected to reflect on their own strengths and weaknesses in terms of interpersonal skills through self-reflection and role-play. They are also given the opportunities to practice different methods to promote their own interpersonal competence through role-play and group discussion. With reference to these learning outcomes, topics covered in the lecture involve basic concepts of interpersonal competence, useful interpersonal skills such as assertiveness and conflict management, the role of interpersonal competence in service leadership and methods of promoting interpersonal competence development.

\section{Concepts and definitions of interpersonal competence}

At the beginning of the lecture, basic concepts of interpersonal competence are introduced. Students are presented with different terms that are used interchangeably in daily lives to represent for interpersonal competence, such as social competence, communication competence, interpersonal skills and social skills. It is highlighted that although many definitions are given, "successful social functioning" is usually intrinsic to the definition of interpersonal competence $[5,6]$. Based on this core definition, various approaches have been developed to measure interpersonal competence, focusing on different indices of "successful social functioning", such as the number of social skills one has developed, "peer status" (i.e. how popular a person is among peers) and "friendship quality" [7].

Specifically, the functional approach to interpersonal competence that focuses on the outcomes of social behavior is introduced. According to this approach, interpersonal competence is assessed in terms of one's ability to achieve personal goals in social interaction while maintaining positive relationships with others [6]. Having a high level of interpersonal competence requires different skills, including interaction and relationship initiation, assertion of personal rights and displeasure with others, self-disclosure, emotional support and management of interpersonal conflict [8]. All the above skills are briefly explained to students, and emphasis is put on "assertion of personal rights and displeasure with others" and "management of interpersonal conflict". These two skills are often ignored and difficult to attain for people living in the Chinese culture where harmonious relationships and conformity are highly emphasized.

In the lecture, elaboration on the two skills and their importance to successful leadership are highlighted to students. First, assertiveness is introduced as legitimate and honest communication and standing up for one's feelings, beliefs, and rights without infringing on the rights of others [9]. Assertiveness serves as an adaptive alternative to maladaptive aggressive and passive behaviors where aggressiveness infringes the rights of others and passiveness implies self-denial and giving up one's own rights 
[10]. Mastering the skills of assertiveness enables individuals to reduce the level of interpersonal conflict and thus reduce a source of daily stress. In organizational settings, assertiveness has been regarded as a prerequisite for effective leadership [11, 12]. Highly assertive people are seen as more powerful than passive employees, and they tend to receive better instrumental outcomes [13].

In addition, conflict resolution as another core interpersonal skill of effective leadership [14] is further introduced, including the related concepts and different types of conflict management strategies. Conflicts happen when the interests or opinions of two parties are at odds with each other. Given that interpersonal interaction forms the major component of organizational life, conflicts are inevitable [15]. Thomas [16] identified five types of conflict management strategies, namely, competing, collaborating, compromising, avoiding and accommodating. The strategies differ in the extent to which individuals balance between self-needs and other's needs. If an individual focuses primarily on self-interest, competing is preferred. If an individual focuses primarily on other's interest, accommodating is preferred. Compromising and collaborating focus on both self and others' needs, with collaborating involving higher levels of coordination and negotiation between the two parties than compromising. Students are reminded that various strategies should be adopted to solve the conflict optimally in different situations and no single strategy is always the best.

\section{Interpersonal competence and service leadership}

Interpersonal competence is regarded as a critical component in many leadership models [17]. In the USFWS Leadership Competency Development Model, interpersonal skill is one of the six foundational leadership competencies [18]. According to this model, interpersonal competence involves treating "others with courtesy, sensitivity, and respect", and considering and responding "appropriately to the needs and feelings of different people in different situations" [18]. Recalling the essence of service leadership that aims to satisfy the needs of self, others and the environment [19], it is thus essential for leaders to develop high interpersonal skills to provide effective service leadership. More importantly, interpersonal competence is embedded in the Chinese implicit theory about leadership. In identifying the dimensions of implicit Chinese concepts of leadership, Ling, Chia and Fang [20] found that in alignment with the collectivistic values of
Chinese culture, interpersonal competence is a primary dimension of Chinese leaders.

In the specific context of service leadership, there are several reasons why interpersonal competence is emphasized. First, service provision requires specific interpersonal skills and etiquette. Given that cornerstones to business success include consideration, cooperation and communication [21], interpersonal skills and business etiquette are necessary to satisfy the needs of clients [22]. Second, interpersonal skills are essential to productivity in a diverse workplace that increasingly utilizes a team approach. Through promoting an atmosphere of confidence and trust, interpersonal skills help develop valuable relationships and inspire a team to accomplish tasks [18]. Third, for service leaders, interpersonal skills are important in the process of communication and coaching. In particular, communication promotes information, thereby increasing employees' participation. Coaching also directly guides employees' performance and helps to solve problems and accomplish organizational objectives $[18,23,24]$.

\section{Outline of the lecture}

The topics and activities for this lecture are summarized in Table 1. Before the formal lecture starts, the lecturer recaps the content of the previous lecture (i.e. intrapersonal competence) by asking the students to recall the key messages of the lecture and ends up by giving a brief summary. After that, the instructor tells a story as a warm-up activity related to interpersonal competence. The story is designed to give the students a first impression about individuals with high or low interpersonal competence and help students link the concept to their daily life experiences.

The first part of the lecture focuses on the basic concepts related to interpersonal competence. Various definitions proposed by different researchers are introduced to students, and the common elements among these definitions are emphasized. In particular, the core message that interpersonal competence refers to one's ability to achieve personal goals in social interaction while maintaining positive relationships with others is conveyed [6]. To facilitate students' understanding, the lecturer highlights several key elements of interpersonal competence. First, interpersonal competence is an ability used in social interactions. Second, it is used for achieving one's own goals because sometimes an individual's needs cannot be fulfilled on their own. Third, interpersonal competence involves skills in initiating a relationship - making the first move to start a relationship. Fourth, to fulfill personal 
Table 1: Overall structure of the lecture.

\begin{tabular}{|c|c|c|}
\hline \multirow{2}{*}{$\begin{array}{l}\text { Activity } \\
\text { Warm-up activity } \\
\text { (10 min) }\end{array}$} & \multicolumn{2}{|l|}{ Procedures } \\
\hline & "Social Butterfly vs. Antisocial Butterfly" & Lecture PPT \\
\hline $\begin{array}{l}\text { Lecture } \\
\text { (15 min) }\end{array}$ & Part I: What is Interpersonal Competence? & Lecture PPT \\
\hline $\begin{array}{l}\text { Role-Play } \\
\text { (21 min) }\end{array}$ & "The Art of Assertiveness" & $\begin{array}{l}\text { Lecture PPT } \\
\text { Appendix } 1\end{array}$ \\
\hline $\begin{array}{l}\text { Lecture } \\
\text { (5 min) }\end{array}$ & Part II: Interpersonal Competences and Service Leadership & Lecture PPT \\
\hline $\begin{array}{l}\text { Lecture } \\
(5 \mathrm{~min})\end{array}$ & Part III: Ways to Promote Interpersonal Competences: Active Listening & Lecture PPT \\
\hline $\begin{array}{l}\text { Role-play } \\
\text { (12 min) }\end{array}$ & “Irritating Habits of Listening" & $\begin{array}{l}\text { Lecture PPT } \\
\text { Appendix } 2\end{array}$ \\
\hline $\begin{array}{l}\text { Lecture } \\
(10 \mathrm{~min})\end{array}$ & Part IV: Ways to Promote Interpersonal Competences: Non-Verbal Communication and Conflict Resolution & Lecture PPT \\
\hline $\begin{array}{l}\text { Group Discussion } \\
\text { (12 min) }\end{array}$ & “Which Strategy Would You Use?” & $\begin{array}{l}\text { Lecture PPT } \\
\text { Appendix } 3\end{array}$ \\
\hline $\begin{array}{l}\text { Wrap-Up } \\
(10 \mathrm{~min})\end{array}$ & Part V: Conclusion & Lecture PPT \\
\hline $\begin{array}{l}\text { Sharing } \\
\text { (5 min) }\end{array}$ & Sharing: Invite two students to share their thoughts after taking this lecture. & N.A. \\
\hline
\end{tabular}

goals, maintaining a relationship across time and settings is also crucial. To further stimulate students' thinking, the instructor invites students to think about the question "why do we need to interact with others?" This question provides a chance for students to reflect on the motivation and gains of social interactions based on their past experiences.

After presenting the basic concepts, five primary domains of interpersonal communication skills are further introduced. Drawing on existing literature [8], interpersonal competence entails competences in the following task domains that have been identified to have theoretical relevance to psychosocial functioning, including (1) interaction and relationship initiation; (2) assertion of personal rights and displeasure with others; (3) selfdisclosure; (4) emotional support; and 5) management of interpersonal conflict. As mentioned earlier, the domains of "assertion of personal rights" and "management of interpersonal conflict" are given more emphases in this lecture.

To promote students' understanding of assertiveness, students are first presented with a series of reflective questions related to their own assertiveness such as whether they have given up their personal interests when in conflict with others to maintain a relationship. Students are then invited to think about their feelings about and reasons for such experiences. The instructor then consolidates the answers of the students by bringing out the issue of antagonism between interpersonal harmony and assertiveness. The significance of this phenomenon is further highlighted with regard to its cultural difference, i.e. the Asians usually focus too much on interpersonal harmony and often sacrifice their own needs, whereas the Westerners are more truthful to themselves and sometimes neglect interpersonal harmony. To echo this viewpoint, the students are then asked to discuss their ratings on a questionnaire they completed earlier regarding their assertiveness to see if their assertiveness has been encouraged/discouraged by society and the people around them (e.g. parents). This discussion leads to the introduction of the definition of assertiveness and further elaboration on the importance of balancing personal needs and the respect for others' needs at the same time during interpersonal interactions. Simple rules to demonstrate one's assertiveness such as "to be direct, open, honest and considerate" are then introduced. Having an initial understanding of assertiveness, each group of students are assigned a scenario in which they need to demonstrate assertiveness through a roleplay activity. After the groups finish their role-plays, the instructor then shows students a list of misconceptions about assertiveness to deepen their understanding and distinguish assertiveness from two related concepts, i.e. aggressiveness and passiveness.

The second part of the lecture deals with the importance of interpersonal competence, particularly its relevance to service leadership. The teacher refers back to the story introduced in the warm-up activity, and then 
highlights the positive outcomes brought by high interpersonal competence, such as having more resources and support, higher personal influence, and better psychological health [25-27]. In an organizational setting, the importance of interpersonal competence is introduced from the roles of leaders $[18,23,24]$ and service providers [19]. The instructor would review the definition of service leadership and link the importance of interpersonal competence to the mission of service leaders.

The third part covers three specific methods to promote interpersonal competence development. First, active listening as a useful interpersonal strategy is taught to students. Students are asked to reflect on the meaning of "active" and how "active" can be shown in listening. The teacher then highlights that passively receiving and interpreting sound information is not "active listening" and introduces six components of active listening: (1) hearing; (2) focusing; (3) comprehending and interpreting; (4) analyzing and evaluating; (5) responding; and (6) remembering [28]. Tips for active listening are demonstrated by the teacher with a real life example. Students are encouraged to participate in another role-play activity in which some irritating habits of listening are present. This activity helps students to experience directly the negative outcomes caused by a lack of active listening from the perspectives of both speakers and listeners.

Second, another method introduced to improve interpersonal competence is promoting one's awareness of the importance of nonverbal communication. To understand the role of nonverbal communication, the students are first shown a short video clip about various body languages to get a first impression. The lecturer then introduces the components of body language and highlights the fact that the majority of one's communication is nonverbal instead of verbal, and nonverbal communication plays an important role in conveying information and attitude, more so than words and vocal qualities [29]. Positive body language in interpersonal communication is also introduced and demonstrated.

The third method of promoting interpersonal competence is to improve conflict resolution skills. The teacher would remind the students that conflicts are inevitable as long as two parties of interests are opposed to or simply different from each other [30]. Therefore, good conflict resolution skills are critical to interpersonal competence. Five strategies of conflict management [16] are introduced, including competing, collaborating, compromising, avoiding and accommodating. Students are then asked to discuss in groups what strategy they would use in a given conflict scenario. After students share their proposed solution to the conflict in class, the teacher sums up by pointing out that the strategies make balance between self-needs and others' needs to different degrees. There is no simple best strategy in dealing with a conflict situation and more than one strategy may be needed in some situations.

After introducing ways to promote interpersonal competence development, the teacher summarizes the lecture by presenting students a list of take-home messages. To further highlight the importance of interpersonal competence to service leadership, the students are then asked to reflect on the core beliefs of service leadership introduced in earlier lectures and their relevance to interpersonal competence.

\section{Activities designed for the lecture}

In addition to lecturing, a variety of activities have been designed for this lecture to facilitate students' learning. According to the transformative learning theory [31, 32], changes and development in learners are obtained through providing them with a chance (e.g. an event on which they could reflect) to examine and challenge their existing way of making meaning out of the world and open themselves to alternatives. In the current lecture focusing on interpersonal competence, different interactive activities are used, including group discussion, self-reflection and role-play. The activities are presented in the following sections.

\section{The first activity (self-reflection): social butterfly vs. antisocial butterfly}

In the first activity, a story about a social butterfly and an anti-social butterfly is presented to the students for them to reflect on their own experiences in which interpersonal competence is involved. Basically, the teacher first tells the story of the two butterflies and their encounters in a social event [33]. Students are then asked to reflect on whether they are familiar with this situation and to rate themselves on a continuum with anti-social butterfly and social butterfly at the two ends. After inviting students to share their ratings and reflection, the teacher wraps up by introducing the topic of the lecture on interpersonal competence focusing on being good at social interactions as 
well as communicating and using various social and communication skills.

\section{The second activity (role-play): the art of assertiveness}

After students have learned basic knowledge about interpersonal competence and the concept of assertiveness, they are invited to practice the art of assertiveness in different scenarios through role-play. Although students may lack experiences of being assertive, they are encouraged to practice the skill in terms of the basic rules introduced in the lecture. Specifically, each group of students is asked to choose one from five different interpersonal communication scenarios (Appendix 1). Based on the scenario, students are requested to think about how to demonstrate assertiveness on that occasion and role play the story in front of the class. After the performance of each group, other students in the class are encouraged to comment on whether assertiveness shown by the group is appropriate and, if not, in what way the performance could be improved. The teacher wraps up the activity by differentiating among assertiveness, aggressiveness and passiveness. It is expected that through this activity, students can directly experience the advantages of "standing up for one's own" and further understand the notion and importance of assertiveness.

\section{The third activity (role-play): irritating habits of listening}

After introducing active listening as a way to promote interpersonal competence, students are required to participate in a second role-play to experience the irritating habits of listening. The purpose of this activity is to increase their understanding about the importance of active listening and the sensitivity to bad listening habits that may inhibit effective communication. By demonstrating the irritating habits of listening, the students could gain the related awareness, reflect on themselves, and develop the intention to abandon bad listening habits. For this activity, first a worksheet is distributed to students of each group (Appendix 2) that lists a series of 13 bad listening habits [34]. Each group is required to pick up three out of the 13 habits listed on the worksheet they consider the most irritating. Two students from each group role-play a conversation scenario and demonstrate the three behaviors.
Following each group's performance, students playing speakers and listeners are invited to take turns to share their difficulties and feelings in the conversation. Finally, the teacher wraps up the activity by further emphasizing the role of active listening in effective communication.

\section{The fourth activity (group discussion): which strategy would you use?}

In the final part of the lecture, students are taught that interpersonal competence involves effectively solving conflicts with different strategies. Several conflict management strategies are introduced to students. This activity aims to help students further understand the importance of applying different conflict coping strategies in different contexts and to provide a chance for students to reflect on the pros and cons of different strategies. In this activity, students are first presented with four scenarios involving various interpersonal conflicts (Appendix 3). They are required to discuss within groups about what strategy they would use to solve the conflict for each scenario. After the discussion, every group will report the strategy they choose for one specific situation and the reasons behind their choice. The teacher wraps up by summarizing the advantages and disadvantages of each strategy and emphasizing that no single strategy is optimal for all conflicts and the importance of solving conflict constructively.

\section{Teacher's personal reflection on teaching the lecture}

While interpersonal competence is a significant aspect in the development of a good service leader, some students are more likely to appreciate this point than others. Students with relatively poor interpersonal competence tend to be more defensive and resistant to the content of this lecture, and therefore the way the teacher conveys the knowledge is crucial. Interactive teaching that utilizes various activities involving self-reflection and experiential learning appears to be an effective way to arouse the interests of these students. More self-disclosure on the part of the teachers would also be helpful. However, the lecturers should stay cautious when introducing some controversial issues to students. Instead of presenting 
a single viewpoint, the lecturer should think critically about the lecture material and try to offer students different perspectives as well as to encourage students to freely express their unique opinions. In addition, more support should be given to students expressing divergent views.

Different methods that promote students' critical selfreflection should be encouraged. Although critical selfreflection could take place in class, it is more likely to take place outside of the classroom [32]. Moreover, although the teachers could provide students with opportunities to examine their assumptions, feelings and viewpoints in the classroom, the depth of their reflection may not be enough. In what ways such self-reflective activities can be effectively facilitated outside the classroom and to a deeper extent is an interesting and valuable topic for future research. Possible strategies may be to give students home assignments in an essay format to stimulate their critical self-reflection or to encourage students to write self-reflective diaries by giving them extra credit. Future teaching may adopt and examine the effectiveness of these methods.
In addition to the topics covered in this lecture, there are other topics that can stimulate the intellectual thinking of students. First, the teacher could encourage students to reflect on the notion of assertiveness in the Chinese culture. It is interesting to ask how one can balance between assertiveness and interpersonal harmony. Second, as contemporary young people are commonly regarded as egocentric [35], students are encouraged to have self-reflection and examination. Third, to help students understand the importance of interpersonal competence, the literature on positive youth development can be introduced [36-38]. In particular, the positive impact of interpersonal competence on the development of young people can help students further appreciate the importance of interpersonal competence in successful service leaders.

Acknowledgments: The Service Leadership project at The Hong Kong Polytechnic University was financially supported by the Victor and William Fung Foundation. The authorship of this paper is equally shared by the first and second authors.

\section{Appendix 1}

\section{Lecture Five: Basic Leadership Competences: Interpersonal Competences}

\section{The Art of Assertiveness}

Assign each group one of the following scenarios by drawing lots. Students in each group are requested to figure out a desirable way to cope with the situation they have drawn and role-play the scene by collective efforts.

Scenario A:

Jennifer always feels that George is a nice guy who cares about her. She really wants to start a romantic relationship with him. One day after class, Jennifer asked George to have dinner with her and left him a note, "Would you be my boyfriend?" Now George is very much entangled. He has no romantic feelings for Jennifer, but he doesn't want to hurt this friend. How could George convey this message to Jennifer with minimum harm caused to her?

\section{Scenario B:}

You are working hard on a group project with several classmates, but Paul appears to be a free rider. To avoid the group progress from being hindered, you decide to tell Paul that he should take his part of the responsibility. In what way(s) can you remind Paul of his responsibility effectively and properly?

\section{Scenario C:}

Carrie is a member of your group. She just submitted her part of the work for a group presentation to the group leader. Although everybody can see the great efforts Carrie has made, her PPT is really not up to standard. How could the group leader convey this message to Carrie in a supportive manner? 


\title{
Scenario D:
}

Linda is your classmate, whom you get along with. Today, when you are having lunch together, Linda asks you to lend your assignment to her for “reference”, hinting that she won't have enough time to finish her work before the deadline and might copy from yours. How would you respond to convey the message that she can only refer to, but not copy your work?

\section{Scenario E:}

You and your friend, Jason, are taking the same course. He just called you and begged you to do him a favor, signing for his attendance in the lecture tomorrow night, because he plans to go for dinner with his girlfriend to celebrate her birthday. How would you tell Jason that such a behavior is not only improper but in essence a criminal offence?

\section{Appendix 2}

\section{Lecture Five: Basic Leadership Competences: Interpersonal Competences}

\author{
Irritating Habits of Listening
}

Below is a checklist of bad listening habits. Please discuss in your group and pick THREE habits that you feel the most irritating by ticking in the corresponding boxes. Then, role-play a conversation scenario in which the listener shows all the three habits you have selected. Other classmates will be invited to guess what the three habits are from your performance.

1. Doesn't give me a chance to talk when I present a problem.

2. Interrupts me when I try to talk.

3. Never looks at me when I talk.

4. Treats me like an inferior.

5. Never smiles.

Note: only the first 5 of the 13 items are listed here due to copyright concerns.

Source: Fritz SM, Brown W, Lunde JP, Banset EA. Interpersonal skills for leadership, 2nd ed. Upper Saddle River: Prentice-Hall, 2004.

\section{Appendix 3}

\section{Lecture Five: Basic Leadership Competences: Interpersonal Competences}

\section{Which Strategy Would You Use?}

Recall the conflict coping strategies you just learned (avoidance, accommodation, compromise, competition and collaboration). Think about which strategy should be used to cope with the conflict in each of the following situations.

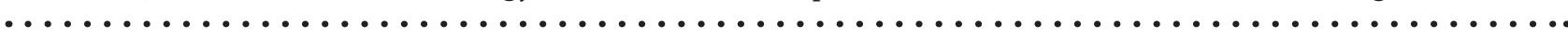

\section{Scenario A:}

It is the end of the semester, and you are working on a group project with Sally. You need one more meeting before the deadline tomorrow. Due to an examination, you are a half hour late for your meeting. Sally shouts at you, stating that you have wasted time and if the project fails, you are responsible for it. You try to explain, but she doesn't listen. Now you have only 3 hours to finish the final part. Which strategy would you use to solve the conflict? Why? 


\section{Scenario B:}

You just gave a wonderful presentation on a topic that you had prepared for a long time. The audience includes several professors in your department, who also praised your work. Now, one person stands up and asserts that your work is no more than repeating what others have done, and there is no innovation, which is obviously not true. You feel very offended. Which strategy would you use to deal with the situation? Why?

\section{Scenario C:}

You, Jim, and Anna, went hiking. After getting off the bus, it was time to find a place for lunch. You expected a big seafood meal at a restaurant nearby, and Jim also showed similar interest. However, Anna said she felt queasy because of carsickness and suggested eating congee. Which strategy would you use? Why?

\section{Scenario D:}

Leon is your friend. Both of you are interns at an electric appliance company. You were just assigned a task to make a marketing plan for a new product. While you emphasize early promotion for attracting as many customers as possible, Leon is more concerned about after-sale service to keep clients. Which strategy would you choose? Why?

\section{References}

1. Shek DT, Yu L, Ma CM, Sun RC, Liu TT. Development of a creditbearing service leadership subject for university students in Hong Kong. Int J Adolesc Med Health 2013;25:353-61.

2. Dweck CS, Leggett EL. A social-cognitive approach to motivation and personality. Psychol Rev 1988;95:256-73.

3. Mezirow J. Transformative learning: theory to practice. N Dir Adult Cont Educ 1997;74:5-12.

4. Dweck CS, Chiu CY, Hong YY. Implicit theories and their role in judgments and reactions: a word from two perspectives. Psychol Inq 1995;6:267-85.

5. Dodge KA. Facets of social interaction and the assessment of social competence in children. In: Schneider BH, Rubin KH, Ledingham JE, editors. Children's peer relations: issues in assessment and intervention. New York, NY: Springer, 1985:3-22.

6. Rubin KH, Rose-Krasnor L. Interpersonal problem solving. In: Van Hassett VB, Hersen M, editors. Handbook of social development. New York: Plenum, 1992:283-323.

7. Rose-Krasnor L. The nature of social competence: a theoretical review. Soc Dev 1997;6:111-35.

8. Buhrmester D, Furman W, Wittenberg MT, Reis HT. Five domains of interpersonal competence in peer relationships. J Pers Soc Psychol 1988;55:991-1008.

9. Delamater RJ, Mcnamara JR. The social impact of assertiveness research findings and clinical implications. Behav Modif 1986;10:139-58.

10. Connor JM, Serbin LA, Ender RA. Responses of boys and girls to aggressive, assertive, and passive behaviors of male and female characters. J Genet Psychol 1978:133:59-69.

11. Gough HG. Testing for leadership with the California Psychological Inventory. In: Clark K, Clark M, editors. Measures of leadership. Greensboro: Center for Creative Leadership, 1990:355-79.

12. Judge TA, Bono JE, Ilies R, Gerhardt MW. Personality and leadership: a qualitative and quantitative review. J Appl Psychol 2002;87:765-80.
13. De Dreu CK, Weingart LR, Kwon S. Influence of social motives on integrative negotiation: a meta-analytic review and test of two theories. J Per Soc Psychol 2000;78:889-905.

14. Heller BR, Drenkard K, Esposito-Herr MB, Romano C, Tom S, Valentine N. Educating nurses for leadership roles. J Contin Educ Nurs 2004;35:203-10.

15. Darling JR, Walker WE. Effective conflict management: use of the behavioral style model. Leadership Organ Dev J 2001;22:230-42.

16. Thomas KW. Thomas-Kilmann conflict mode instrument. Tuxedo, NY: Xicom, 1974.

17. Lussier RN, Achua CF. Organizational leadership and change. In: Lussier RN, Achua CF, editors. Leadership: theory, applications, skill development, 4th ed. Mason: South-Western College Publishers, 2010:372-409.

18. National Conservation Training Center. Foundational leader competencies: interpersonal skills. US Fish and Wildlife Service, National Conservation Training Center, 2010. Available at: http://nctc.fws.gov/led/competencymodel/Foundational/interpersonal.html. Accessed: 15 May 2013.

19. Chung P. Hong Kong Institute of Service Leadership and Management curriculum framework. Hong Kong: Hong Kong Institute Leadership Management, 2011.

20. Ling W, Chia RC, Fang L. Chinese implicit leadership theory. J Soc Psychol 2000;140:729-39.

21. Pearse JR. Teaching the 3 Co's in the engineering classroom. Paper presented at: ASEE Annual Conference and Exposition; 2005 June 12-15; Portland, Oregon.

22. Casperson DM. Easy ways to gain new client: business etiquette is the key. CMA Manage 2000;23:13-4.

23. Guo KL, Anderson D. The new health care paradigm: roles and competencies of leaders in the service line management approach. Leadership Health Serv 2005;18:12-20.

24. Lovett $M$, Jones I. Social/interpersonal skills in business: in field, curriculum and student perspectives. J Manage Mark Res 2008;1:1-13.

25. Chen G, Chung J. The impact of Confucianism on organizational communication Commun Quart 1994;42:93-105. 
26. Norton R, Warnick B. Assertiveness as a communication construct. Hum Commun Res 1976;3:62-6.

27. Weaver RL. Understanding interpersonal communication. New York, NY: Harper, 1996.

28. Sayre JM. Focus. In: Coakley CG, Wolvin AD, editors. Experiential listening: tools for teachers and trainers. New Orleans, LA: Spectra, 1989.

29. Brooks W, Heath R. Speech communication. Dubuque, IA: William C Brown, 1995.

30. Amason A, Thompson K, Hochwarter W, Harrison A. Conflict: an important dimension in successful management teams. Organ Dynam 1995;24:20-35.

31. Mezirow J. Transformative dimensions of adult learning. San Francisco, CA: Jossey-Bass Publishers, 1991.

32. Cranton P. Teaching for transformation. N Dir Adul Contin Educ 2002;93:63-72.
33. Sedeen A. Anti-social butterfly. Available at: http://doodledujour. com/post/1080/anti-social-butterfly. Accessed: 15 May 2013.

34. Fritz SM, Brown W, Lunde JP, Banset EA. Interpersonal skills for leadership, 2nd ed. Upper Saddle River: Prentice-Hall, 2004.

35. Shek DT, Wong KK. Do adolescent developmental issues disappear overnight? Reflections about holistic development in university students. ScientificWorldJ 2011;11:353-61.

36. Shek DT, Sun RC, Merrick J. Positive youth development constructs: conceptual review and application. ScientificWorldJ 2012;2012:15923.

37. Shek DT, Sun RC. The Project P.A.T.H.S. in Hong Kong: development, training, implementation, and evaluation. J Pediatr Adolesc Gynecol 2013;26:S2-9.

38. Shek DT, Sun RC, editors. Development and evaluation of positive adolescent training through holistic social programs (P.A.T.H.S.). Berlin: Springer, 2013. 